Journal of Dental Science and Therapy

\title{
Molecular Characterization of Candida parapsilosis Species Complex in Niches of the Oral Cavity in a Cohort of Patients from Argentina with Different Oral and Dental Clinical Manifestations \\ Rodríguez $\mathrm{L}^{1,2^{*}}$, Jewtuchowicz $\mathrm{V}^{1,3}$
}

${ }^{1}$ Universidad de Buenos Aires, Facultad de Medicina, Centro de Micología, IMPaM, UBA-CONICET, Capital Federal, CABA, Argentina ${ }^{2}$ Docente titular de las cátedras de Semiología y Clínica de Diagnóstico, Facultad de Odontología-Universidad de Cuenca-Ecuador ${ }^{3}$ Hospital HIGA-Gandulfo-Provincia de Buenos Aires-Argentina

\begin{abstract}
*Corresponding author: Rodríguez L, Universidad de Buenos Aires, Facultad de Medicina, Centro de Micología, IMPaM, UBACONICET, Capital Federal, CABA, Argentina; E mail: malourdes84@hotmail.com
\end{abstract}

Article Type: Research, Submission Date: 15 February 2016, Accepted Date: 11 April 2016, Published Date: 06 May 2016.

Citation: Rodríguez L and Jewtuchowicz V (2016) Molecular Characterization of Candida parapsilosis Species Complex in Niches of the Oral Cavity in a Cohort of Patients from Argentina with Different Oral and Dental Clinical Manifestations. J. Dent. Sci. Ther 1(1): 18-25. doi: https://doi.org/10.24218/jdst.2016.05.

Copyright: @ 2016 Rodríguez L and Jewtuchowicz V. This is an open-access article distributed under the terms of the Creative Commons Attribution License, which permits unrestricted use, distribution, and reproduction in any medium, provided the original author and source are credited.

\section{Abstract}

Candida parapsilosis is considered to be a complex of three species due to genetic heterogeneity. Currently, it is the second most isolated yeast in bloodstream infections and oral cavity sites with C. parapsilosis sensu stricto and C. metapsilosis being the species mostly recovered from oral niches in both healthy and immunecompromised patients respectively. Disparity in antifungal susceptibility has been reported among species of this complex, while no data on distribution and behavior in the oral cavity has been reported in Argentina.

Objective: To molecularly characterize a collection of isolates from Argentina, phenotypically identified as C. parapsilosis from different oral niches, in a cohort of patients with different oral and dental clinical conditions.

Methodology: This experimental study used 31 yeasts phenotypically recognized as $C$. parapsilosis and recovered for molecular characterization by end-point PCR using specific primers. The in vitro sensitivity of isolates against azoles, echinocandins, amphotericin and flucytosine was evaluated by automated Vitek2 system and MIC (Minimum Inhibitory Concentration) in line with CLSI (Clinical and Laboratory Standards Institute) M27-A3 guidelines.

Results: All isolates, $100 \%$ (31/31), were positive for C. parapsilosis sensu stricto species. Of these, $77.4 \%$ were recovered in oral inflammatory conditions, and $94.7 \%$ of the strains analyzed for antifungal susceptibility profile showed favorable response to all drugs tested.

Conclusions: C. parapsilosis sensu strictois a common colonizing of the oral mucosa under pathological conditions, and generally shows favorable response to antifungal agents commonly used in clinical practice, but with a tendency to lower responsiveness to azoles and echinocandins.

Keywords: Candidaparapsilosiscomplex, Periodontaldisease, Minimum inhibitory concentration, Clinical and laboratory institute.

\section{Introduction}

Candida species have emerged as important pathogens over the last two decades[1], and invasive candidiasis (IC) is one of the most common causes of nosocomial invasive infectious diseases[2](Miranda et al. 2011). Although Candida albicans species remains the predominant etiologic agent, $>50 \%$ of candidaemia cases and IC can result from non-albicans Candida species[2] (Miranda et al) with Candida parapsilosis being the second or third yeast species in this group most commonly isolated from blood cultures in Latin America, Canada, Europe, and Asia[1](Ge et al, 2012).

The Candida parapsilosis complex is composed of three different species: Candida parapsilosis sensu stricto, Candida orthopsilosis, and Candida methapsilosis, phenotypically indistinguishable but genetically heterogeneous[3] (Silva, 2009), which means that for discrimination at the species level, it is necessary to conduct molecular biology techniques for its typing[4], and although many of them have been described, there is not an established molecular technique to be used as reference yet. The techniques studied include karyotyping, isoenzyme typing, multilocus sequence typing (MLST), restriction fragment length polymorphism analysis (RFLP), amplified fragment length polymorphism (AFLP), randomly amplified polymorphic DNA (RAPD) and DNA sequencing[5] (2).

Results are highly variable based on the species distribution of this complex. While literature reviews show a higher prevalence of Candida parapsilosis sensu stricto worldwide, with this being the most isolated species of hematogenous infections, the distribution of Candida orthopsilosis and Candida methapsilosis is quite heterogeneous, which varies according to geographic regions, clinical sites and anatomical sites[1,6].

Little is known about the prevalence of Candida parapsilosis complex species in the oral cavity. The few published works on the subject report varying results on the distribution of the complex in this specific ecological niche, emphasizing that $C$ parapsilosis 
Citation: Rodríguez L and Jewtuchowicz V (2016) Molecular Characterization of Candida parapsilosis Species Complex in Niches of the Oral Cavity in a Cohort of Patients from Argentina with Different Oral and Dental Clinical Manifestations. J. Dent. Sci. Ther 1(1): 18-25. doi: https://doi. org/10.24218/jdst.2016.05.

sensu stricto is the species mostly recovered in immunocompetent individuals either in Europe or in North America [3,7,8], while $C$. methapsilosis might apparently predominate over C. parapsilosis sensu stricto in immunocompromised patients. Evidence of this is the result of the study presented by Moris DV et al, who found in oral cavity of patients with HIV, a total prevalence of $4.7 \%$ with $2.2 \%$ of C. parapsilosis sensu estrico and $2.5 \%$ of C. methapsilosis, but did not find the presence of C. orthopsilosis[9].

Regarding the behavior of Candida parapsilosis sensu stricto in the oral cavity, no data was found.

Variability in antifungal susceptibility profiles has been reported among species of this complex[10], besides the decreased susceptibility of $C$. parapsilosis sensu stricto to azoles and echinocandins $[3,7,10,11]$. The development and subsequent expansion of nosocomial C. parapsilosis resistant to these drugs have major clinical implications. Therefore, continuous monitoring of the emergence of this multidrug-resistant phenotype of $C$. parapsilosis is clearly justified.

Despite the importance of C. parapsilosis as a nosocomial fungal pathogen, there are few studies, focused especially on Latin America, based on the global epidemiology and on the response to anti-fungal species of this complex, let alone the knowledge about the distribution complex in oral cavity niches which can be a source of candidemia caused by this fungus in groups with risk factors. In Argentina, scarce data reveals species distribution and response to antifungals within this complex. Therefore, our group was aimed to study the prevalence, distribution in mouth and response to antifungals of the 3 species of the C. parapsilosis complex in a collection of clinical isolates obtained in previous research studies which were referred to the Mycology Center of the School of Medicine, University of Buenos Aires (UBA), and Gandulfo Hospital.

\section{Methods}

In this experimental and retrospective study, 31 clinical isolates of the Candida parapsilosis complex from outpatients and immunocompetent patients, and from different oral cavity niches obtained from previous research studies which had been referred from the collection of the for Mycology Center, School of Medicine-UBA and Gandulfo Hospital between January 2006 and December 2007, including the clinical records of the patients and data on oral isolates.

The inclusion and exclusion criteria used for specimen collection were:

Inclusion criteria: Adult, immunocompetent and non-smoker individuals, aged between 18 and 50 years, with and without periodontal disease based on clinical indicators obtained by pressure-controlled periodontal probing; with or without intraoral instruments.

Exclusion criteria: Individuals with systemic diseases affecting the gum and periodontal status; Patients who had received antibiotics, anti-inflammatory or anti-fungal treatment six months prior to specimen collection and patients who had received periodontal treatment six months prior to the study. Patients who rejected to participate in the study after being duly informed were also excluded.

Rejection criteria: For ethical reasons, patients requiring the application of local or systemic surgical complementary and/or pharmacological therapies were not enrolled in the study, as well as smokers and pregnant women.

\section{Experimental design}

All stored specimens identified as Candida parapsilosis, based on conventional phenotypic methods, and referred from previous studies, were processed. Of the total samples analyzed, 31 isolates were successfully reconstituted and could be molecularly characterized by endpoint PCR.

ATCC reference strains were used: C. parapsilosis (ATCC 22019), C. orthopsilosis (ATCC 96139) and C. methapsilosis (ATCC 96143) and subjected to the same procedures used for the clinical isolates:

\section{Phenotypic reconstitution}

Stored isolates were recovered and seeded in culture media:

- BHI (brain-heart infusion) for metabolic activation of strains, with $24-48 \mathrm{~h}$ incubation at $28-37^{\circ} \mathrm{C}$.

- Solid differential chromogenic medium for the detection of Candida (CHROMagar) to specify the purity of the isolate and rule out contaminated strains, with $28^{\circ} \mathrm{C}$ incubation.

- Sabouraud, to obtain amplification of colonies for $24 \mathrm{~h}$ at $28^{\circ} \mathrm{C}$ incubation.

- YPD broth (yeast extract, peptone and glucose) to obtain a pure culture at $37^{\circ} \mathrm{C}$, stirring for $24 \mathrm{~h}$.

Isolates were identified on the basis of the color developed in chromogenic medium, micro-morphology in milk 1\%-Tween 80 agar, and carbohydrate assimilation profile API ID 32D and Vitek2 (bioMerieux, France) trading systems.

\section{Molecular identification of the $C$. parapsilosis complex through the following steps}

- Extraction of DNA from the yeast following the protocol described in Scherer and Stevens 1987, using zymolyase and column purification (QIAamp DNA Blood Kit), for which the Qiagen protocol was followed. DNA was stored at $-20^{\circ} \mathrm{C}$

- Inspection of DNA by electrophoresis

- Quantification and quality control of DNA by spectrophotometry

- DNA dilution in 1:10 ratio

- Molecular typing of species of the complex by endpoint polymerase chain reaction (endpoint PCR), using specific primers obtained from unique sequences contained in the internal transcription spacer 1 (ITS 1)-5.8 rRNA-ITS2 of the fungal ribosomal DNA, which allow to obtain a specific sequence of the C. parapsilosis sensu stricto, C. orthopsilosis and C. methapsilosis species separately (Table 1)

\section{Antifungal susceptibility profile}

In vitro susceptibility was evaluated on 6 antifungals commonly used in clinical practice in mycosis: fluconazole (FLC), voriconazole (VRC), caspofungin (Caspo), micafungin (MICA), amphotericin B (AMB), flucytosine (FLUCY) through minimal inhibitory concentration (MIC) in line with the CLSI ("Clinical and Laboratory Standards Institute") guidelines, document M27- 
Citation: Rodríguez L and Jewtuchowicz V (2016) Molecular Characterization of Candida parapsilosis Species Complex in Niches of the Oral Cavity in a Cohort of Patients from Argentina with Different Oral and Dental Clinical Manifestations. J. Dent. Sci. Ther 1(1): 18-25. doi: https://doi. org/10.24218/jdst.2016.05.

Table 1: Sequence of primers used for rapid identification of the $C$. parapsilosis complex at species level

\begin{tabular}{|c|c|c|c|c|c|}
\hline Primer & Gen target & Direction & Species Specificity & Sequence & Amplicon size \\
\hline CPAF & ITS 1 & Forward & C. parapsilosis & TTTGCTTTGGTAGGCCTTCTA & $379 \mathrm{bp}$ \\
\hline CPAR & ITS 2 & Reverse & & GAGGTCGAATTTGGAAGAAGT & $367 \mathrm{bp}$ \\
\hline CORF & ITS 1 & Forward & C. orthopsilosis & TTTGGTGGCCCACGGCCT & \\
\hline CORR & ITS 2 & Reverse & & TGAGGTCGAATTTGGAAGAATT & $374 \mathrm{bp}$ \\
\hline CMEF & ITS 1 & Forward & C. methapsilosis & TTTGGTGGGCCCACGGCT & \\
\hline CMER & ITS 2 & Reverse & & GAGGTCGAATTTGGAAGATGT & \\
\hline
\end{tabular}

Source: Asadzadeh M, et al. 2009 [12].

A3 and by the automated Vitek2 (Biomerieux) system.

Strains of Candida albicans ATCC 90028, Candida parapsilosis ATCC 22019 and C. krusei ATCC 6258 were included as control.

For the interpretation of MICse, species-specific score cutoff values were used, reconsidered by the CLSI Subcommittee led by Pfaller and Diekema, and published in the Journal of Microbiology-2012[13].

\section{Statistical analysis}

Data were processed in the Microsoft Excel 2010 software, STATISTIX 7.0 and SPSS v11.0 for quantitative and qualitative analyses, with a 95\% CI, and chi-square test for statistical significance.

\section{Results}

Molecular identification of species of the parapsilosiscomplex in clinical isolates previously identified as Candida parapsilosis by conventional methods

A total of 31 C. parapsilosis strains were recovered and evaluated by molecular methods. Strains were isolated from different oral niches: buccal mucosa, palatal mucosa, tongue and gingival sulcus. Of the 31 strains, 7 were obtained from a collection of isolates of the Mycology Center-UBA, and 24 were referred from Gandulfo Hospital (Table 2).

All isolates, $100 \%$ (31/31), were positive for C. parapsilosis sensu stricto species by endpoint PCR using the specific primer pair CPAR-CPAF, obtaining amplicons of equal size to 379bp (Figures. $1,2)$. This banding pattern is compatible with that in Asadzadeh $\mathrm{M}$ et al, published in the Journal of Medical Microbiology of 2009[12].

\section{Distribution of $C$. parapsilosis sensu stricto according to oral clinical condition}

When the species found were associated with the oral condition of the patients at the time of sampling (as reported in the medical history) it was found that six of the $31(19.4 \%)$ strains were isolated in gingivitis conditions, 18 of the 31 (58.1\%) positive for C. parapsilosis sensu stricto strains were isolated in periodontitis conditions, while 7 of the $31(22.5 \%)$ sensu stricto strains were isolated in oral health conditions (Table 3 ).

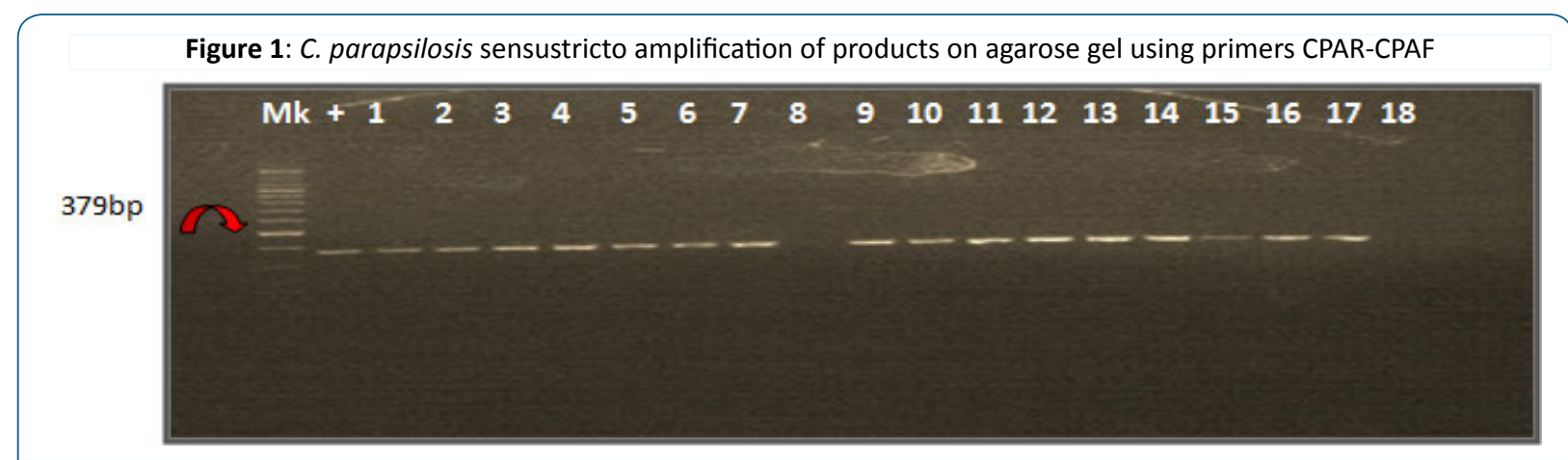

Note: Mk: weight marker; +: positive control; 1,2,3,4,5,6,7,9,10,11,12,13,14,15,16,17: clinical samples; 8 , 18: negative controls.

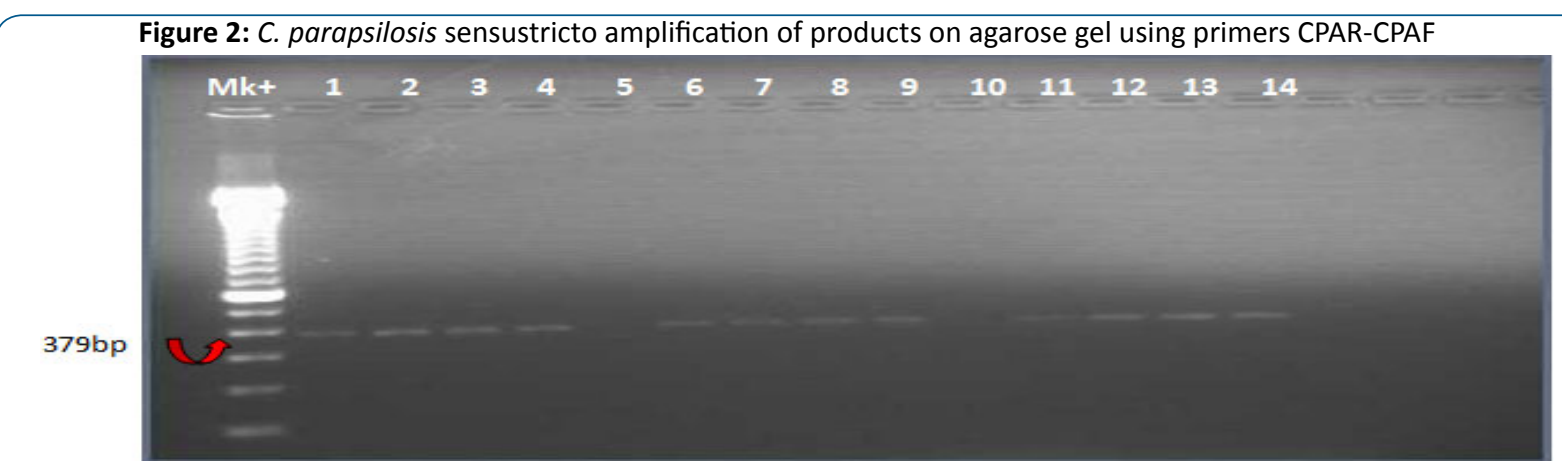

Note: Mk: weight marker; +: positive control; 1,2,3,5,6,7,8,10,11,12,13: clinical samples; 4,9,14: negative controls. 
Citation: Rodríguez L and Jewtuchowicz V (2016) Molecular Characterization of Candida parapsilosis Species Complex in Niches of the Oral Cavity in a Cohort of Patients from Argentina with Different Oral and Dental Clinical Manifestations. J. Dent. Sci. Ther 1(1): 18-25. doi: https://doi. org/10.24218/jdst.2016.05.

Table 2: Molecular identification of 31 isolates previously defined by phenotypic methods as $C$. parapsilosis

\begin{tabular}{|c|c|c|c|}
\hline Strain & Origen & Nich & Species \\
\hline 10.2 & Gandulfo & Oral mucosa & Sensu stricto \\
\hline 13.2 & Gandulfo & Oral mucosa & Sensu stricto \\
\hline $15 \mathrm{~A}$ & Gandulfo & Subgingival & Sensu stricto \\
\hline 51.2 & Gandulfo & Oral mucosa & Sensu stricto \\
\hline 14.2 & Gandulfo & Oral mucosa & Sensu stricto \\
\hline 15.1 & Gandulfo & Oral mucosa & Sensu stricto \\
\hline 16.1 & Gandulfo & Oral mucosa & Sensu stricto \\
\hline 23.2 & Gandulfo & Oral mucosa & Sensu stricto \\
\hline 7.2 & Gandulfo & Oral mucosa & Sensu stricto \\
\hline 11.1 & Gandulfo & Oral mucosa & Sensu stricto \\
\hline 36.1 & Gandulfo & Oral mucosa & Sensu stricto \\
\hline $53 \mathrm{~A}$ & Gandulfo & Subgingival & Sensu stricto \\
\hline $40 \mathrm{~A}$ & Gandulfo & Subgingival & Sensu stricto \\
\hline $12 \mathrm{~A}$ & Gandulfo & Subgingival & Sensu stricto \\
\hline $50 \mathrm{~A}$ & Gandulfo & Subgingival & Sensu stricto \\
\hline 50.1 & Gandulfo & Oral mucosa & Sensu stricto \\
\hline $73 \mathrm{~A}$ & Gandulfo & Subgingival & Sensu stricto \\
\hline $16 \mathrm{~A}$ & Gandulfo & Subgingival & Sensu stricto \\
\hline $23 \mathrm{~B}$ & Gandulfo & Subgingival & Sensu stricto \\
\hline $32 \mathrm{~B}$ & Gandulfo & Subgingival & Sensu stricto \\
\hline $75 \mathrm{CA}$ & Gandulfo & Cheek & Sensu stricto \\
\hline $78 \mathrm{LE}$ & Gandulfo & Tongue & Sensu stricto \\
\hline $6 \mathrm{LE}$ & Gandulfo & Tongue & Sensu stricto \\
\hline $6 \mathrm{PA}$ & Gandulfo & Palate & Sensu stricto \\
\hline 4220 & Micology Center & Oral mucosa & Sensu stricto \\
\hline 4757 & Micology Center & Oral mucosa & Sensu stricto \\
\hline 5299 & Micology Center & Oral mucosa & Sensu stricto \\
\hline 5301 & Micology Center & Oral mucosa & Sensu stricto \\
\hline 5462 & Micology Center & Oral mucosa & Sensu stricto \\
\hline 6912 & Micology Center & Oral mucosa & Sensu stricto \\
\hline 7066 & Micology Center & Oral mucosa & Sensu stricto \\
\hline & & & \\
\hline
\end{tabular}

Table 3: Relationship of parapsilosis species complex with oral clinical condition: $77.4 \%$ of the isolates were isolated in inflammatory oral conditions

\begin{tabular}{|c|c|c|c|c|}
\hline Species & Gingivitis & Periodontitis & Oral condition & Total \\
\hline Sensu stricto & $6(19.4 \%)$ Cl95\%:7.5-37.5 & 18(58.1\%)Cl95\%:39.3-74.9 & $7(22.5 \%) C 195 \%: 9.6-41.1$ & $31(100 \%)$ \\
\hline Orthopsilosis & 0 & 0 & 0 & 0 \\
\hline Metapsilosis & 0 & 0 & 0 & 0 \\
\hline Total & $19.4 \%$ & $58.1 \%$ & $22.5 \%$ & $100 \%$ \\
\hline
\end{tabular}

${ }^{*} p($ Fisher $)=0.000016(\mathrm{CHI} 2$ (Yates) $=16.5161 ; G L=1 ; p=0) \%$

\section{Distribution of $C$. parapsilosis sensu stricto according to presence or absence of intraoral appliances}

When the species found were associated with the use of intraoral appliances, it was found that of the 31 strains characterized as $C$. parapsilosis sensu stricto, 17 (54.8\%) belonged to patients with some kind of intraoral device (orthodontics, removable and fixed prostheses, partial and total) and $14(45.2 \%)$ belonged to patients without intraoral appliances (Table 4).

Table 4: Distribution of $C$. parapsilosis sensu stricto species in the presence or absence of intraoral appliances

\begin{tabular}{|c|c|}
\hline Intraoral appliances & Sensu stricto species \\
\hline Presence & $17(54.8 \%)$ \\
\hline Absence & $14(45.2 \%)$ \\
\hline Total & $\mathbf{3 1}(\mathbf{1 0 0 \% )}$ \\
\hline
\end{tabular}

${ }^{*} p($ Fisher $)=0.305933(\mathrm{CHI} 2$ (Yates $\left.)=0.2581 ; \mathrm{GL}=1 ; \mathrm{p}=0.6115\right)$

\section{Antifungal susceptibility profile}

Of the 31 strains characterized as C. parapsilosissensu stricto, 19 were tested for antifungal susceptibility to six drugs commonly used in clinical practice.

According to the species-specific cut-off values proposed by the CLSI Subcommittee in 2012, 18 of the 19 (94.7\%) strains were sensitive to all the antifungals tested, although not determined (ND) for ANFO and FLUCY as there are no clinical breakpoints (CBPs) established for these two drugs yet. Only one strain isolated from the tongue showed high MIC values for FLC, VRC and CASPO (Table 5). For this particular case, the FLC MIC corresponded with a dose-dependent sensitivity; and the VRC MIC and CASPO corresponded with intermediate sensitivity to this drug. In line with the epidemiological cut-off value (ECV) proposed by the CLSI Subcommittee in 2012, this strain isolated from the tongue corresponded with a non-wildtype (non-WT) strain that developed resistance mechanisms (Table 6). Therefore, the frequency of resistance or reduced susceptibility found in the 
Citation: Rodríguez L and Jewtuchowicz V (2016) Molecular Characterization of Candida parapsilosis Species Complex in Niches of the Oral Cavity in a Cohort of Patients from Argentina with Different Oral and Dental Clinical Manifestations. J. Dent. Sci. Ther 1(1): 18-25. doi: https://doi. org/10.24218/jdst.2016.05.

Table 5: MIC of each drug for the 19 strains studied

\begin{tabular}{|c|c|c|c|c|c|c|c|}
\hline Strain No & Species & FLC & VRC & CASPO & MICA & AMB & FLUCY \\
\hline 10.2 & Sensu estricto & MIC: $<=2$ & MIC: $<=0.12$ & MIC: 1 & MIC: 0.5 & MIC: $<=0.25$ & MIC: $<=1$ \\
\hline 13.2 & Sensu estricto & MIC: $<=1$ & MIC: $<=0.12$ & MIC: 1 & MIC: 0.5 & MIC: $<=0.25$ & MIC: $<=1$ \\
\hline $15 A$ & Sensu estricto & MIC: 1 & MIC: $<=0.12$ & MIC: 0.5 & MIC: 0.5 & MIC: $<=0.25$ & MIC: $<=1$ \\
\hline 14.2 & Sensu estricto & MIC: 2 & MIC: $<=0.12$ & MIC: 1 & MIC: 0.5 & MIC: $<=0.5$ & MIC: $<=1$ \\
\hline 15.1 & Sensu estricto & MIC: $<=1$ & MIC: $<=0.12$ & MIC: 0.5 & MIC: 0.5 & MIC: $<=0.25$ & MIC: $<=1$ \\
\hline 16.1 & Sensu estricto & MIC: $<=1$ & MIC: $<=0.12$ & MIC: 0.5 & MIC: 0.5 & MIC: $<=0.25$ & MIC: $<=1$ \\
\hline 23.2 & Sensu estricto & MIC: $<=1$ & MIC: $<=0.12$ & MIC: 0.5 & MIC: 0.5 & MIC: $<=0.5$ & MIC: $<=1$ \\
\hline 11.1 & Sensu estricto & MIC: 2 & MIC: $<=0.12$ & MIC: 1 & MIC: 0.5 & MIC: $<=0.5$ & MIC: $<=1$ \\
\hline 36.1 & Sensu estricto & MIC: $<=1$ & MIC: $<=0.12$ & MIC: 0.25 & MIC: 0.06 & MIC: $<=0.5$ & MIC: $<=1$ \\
\hline $53 A(2)$ & Sensu estricto & MIC: $<=1$ & MIC: $<=0.12$ & MIC: 0.5 & MIC: 0.5 & MIC: $<=0.25$ & MIC: $<=1$ \\
\hline $40 A$ & Sensu estricto & MIC: 2 & MIC: $<=0.12$ & MIC: 1 & MIC: 0.5 & MIC: $<=0.25$ & MIC: $<=1$ \\
\hline $12 A$ & Sensu estricto & MIC: $<=1$ & MIC: $<=0.12$ & MIC: 0.5 & MIC: 0.5 & MIC: $<=0.25$ & MIC: $<=1$ \\
\hline $50 A$ & Sensu estricto & MIC: $<=1$ & MIC: $<=0.12$ & MIC: 0.5 & MIC: 0.5 & MIC: $<=0.5$ & MIC: $<=1$ \\
\hline 50.1 & Sensu estricto & MIC: $<=1$ & MIC: $<=0.12$ & MIC: 0.5 & MIC: 0.5 & MIC: $<=0.5$ & MIC: $<=1$ \\
\hline $73 A$ & Sensu estricto & MIC: $<=1$ & MIC: $<=0.12$ & MIC: 0.5 & MIC: 0.5 & MIC: $<=0.25$ & MIC: $<=1$ \\
\hline $16 A$ & Sensu estricto & MIC: 2 & MIC: $<=0.12$ & MIC: 1 & MIC: 0.5 & MIC: $<=0.25$ & MIC: $<=1$ \\
\hline $78 L E$ & Sensu estricto & MIC: 4 & MIC: $<=0.25$ & MIC $>=4$ & MIC: 0.5 & MIC: $<=0.25$ & MIC: $<=1$ \\
\hline $6 L E$ & Sensu estricto & MIC: $<=1$ & MIC: $<=0.12$ & MIC: 0.5 & MIC: 0.5 & MIC: $<=0.25$ & MIC: $<=1$ \\
\hline $6 P A$ & Sensu estricto & MIC: $<=1$ & MIC: $<=0.12$ & MIC: 0.5 & MIC: 0.5 & MIC: $<=0.25$ & MIC: $<=1$ \\
\hline
\end{tabular}

Table 6: Strain 78LE, according to the International Scale, is non-WT; with DDS to FLC; IS to VRC and CASPO

\begin{tabular}{|c|c|c|c|c|c|c|}
\hline \multirow{2}{*}{ Drug } & \multirow{2}{*}{ MIC (ug/ml) } & \multicolumn{3}{|c|}{ CBPs } & \multicolumn{2}{|c|}{ ECV } \\
\hline & & s & DDS/IS & $\mathbf{R}$ & WT & Non-WT \\
\hline FLC & 4 & & $x$ & & & $x$ \\
\hline VRC & 0.25 & & $x$ & & & $x$ \\
\hline CASPO & 4 & & $x$ & & & $x$ \\
\hline
\end{tabular}

Note: CBPs: clinical breakpoint; ECV: Epidemiologic cut-off value; S: sensitive; DDS: dose dependent sensitivity; IS: intermediate sensitivity; R: resistant; WT: wild type; Non-WT: Non-wild type

19 strains studied was $5.26 \%$ (Table 7).

The $\mathrm{MIC}_{50}$ and $\mathrm{MIC}_{90}$ of each antifungal were quite low in this study, including coinciding with 4 drugs: VRC, CASPO, MICA and FLUCY. This means that the strains were very responsive to said antifungals (Table 7 ).

Table 7: MIC values and resistance frequency/reduced susceptibility to the 6 antifungals tested in 19 of $C$. parapsilosis sensu stricto strains

\begin{tabular}{|c|c|c|c|c|c|c|}
\hline Drug & No. & MIC $_{50}$ & MIC $_{90}$ & MIC range & \%S & \%R/RS \\
\hline FLC & 19 & $\leq 1$ & 2 & 1 a 4 & $94.7 \%$ & $5.26 \%$ \\
\hline VRC & 19 & $\leq 0.12$ & $\leq 0.12$ & 0.12 a 0.25 & $94.7 \%$ & $5.26 \%$ \\
\hline CASPO & 19 & 0.5 & 0.5 & 0.5 a 4 & $94.7 \%$ & $5.26 \%$ \\
\hline MICA & 19 & 0.5 & 0.5 & 0.06 a 0.5 & $100 \%$ & $0.0 \%$ \\
\hline AMB & 19 & $\leq 0.25$ & $\leq 0.5$ & 0.25 a 0.5 & ND & ND \\
\hline FLUCY & 19 & $\leq 1$ & $\leq 1$ & 1 a 1 & ND & ND \\
\hline
\end{tabular}

Note: $\mathrm{S}=$ sensitivity; $\mathrm{R}=$ resistance; $\mathrm{RS}=$ reduced susceptibility.

\section{Discussion}

Candida parapsilosis is currently considered an emerging nosocomial pathogen[14], and its growing resistance to the azole and echinocandins groups $[3,7,10,11]$ has placed it in the spotlight in recent years. It is an integrated complex composed of 3 species phenotypically indistinguishable, but due to its genetic heterogeneity, such discrimination is possible using molecular techniques only.

In 2005, Tavanti et al. proposed the analysis of restriction fragment length polymorphisms of the SADH gene, which encodes the secondary alcohol dehydrogenase enzyme and is common in the three species[15]. However, there is no standard technique for such discrimination; and in 2009 Asadzadeh et al presented the results of a study based on the molecular characterization of species of this complex in a collection of clinical isolates from Kuwait, using a simple technique based on the use of specific primers obtained from unique sequences within the ITS1-5.8SrRNA-ITS2 region, which allows the collection of each species separately. They validated their results using the automated sequencing technique by Sanger[12].

Within this complex, C. parapsilosis sensu stricto is the species most isolated from clinical isolates derived of both immunocompetent patients either in pathological conditions or commensal $[1-3,6,7,9,14,16]$. This fact has been backed up by many studies worldwide. However, there are few studies that describe the prevalence and distribution of the species involved in this complex at health or oral conditions levels. To date, it is generally acknowledged that C. parapsilosissensu stricto is the most prevalent species in the oral cavity niche of immunocompetent individuals, regardless of the geographical region. This has been reported in studies conducted in the USA [8], Portugal[3], Turkey[7] and China[1]. A single study in Brazil, analyzed the distribution of species involved in this complex in the oral cavity of chronic HIV-patients, in which C. metapsilosis was the most isolated species followed by $C$. parapsilosis sensu stricto, although the difference they found was not statistically significant, and the sample size was very small[9]. 
Citation: Rodríguez L and Jewtuchowicz V (2016) Molecular Characterization of Candida parapsilosis Species Complex in Niches of the Oral Cavity in a Cohort of Patients from Argentina with Different Oral and Dental Clinical Manifestations. J. Dent. Sci. Ther 1(1): 18-25. doi: https://doi. org/10.24218/jdst.2016.05.

The present study involved the isolation of C. parapsilosis sensu stricto only, obtaining $100 \%$ prevalence in all the samples analyzed from immunocompetent patients' oral niches. This result is similar to that reported by other authors such as Ghanoun et al (2010)[8]; Enger et al (2001)[25]; Silva et al (2009)[3]; Ge et al
Pfaller and Diekema (2012),[13] it could be observed that $100 \%$ of the strains were resistant to FLUCY, since regarding the ECV, the MIC of FLUCY equal to or lower than $0.5 \mathrm{ug} / \mathrm{mL}$ corresponded to a WT strain, while a MIC higher to $0.5 \mathrm{ug} / \mathrm{mL}$ indicated that a non-WT strain developed resistance mechanisms. But the British

Table 8: Distribution of $C$. parapsilosis species complex in oral niches; summary of reports

\begin{tabular}{|c|c|c|c|c|}
\hline & \multicolumn{3}{|c|}{ Number of isolates (\%) per species } & Origen \\
\hline Author & C. parapsilosis & C. orthopsilosis & C. metapsilosis & Reference \\
\hline Ghannoum et al & 3 & 0 & 1 & China (2012) \\
\hline Ge et al & 2 & 0 & 1 & Brazil (2014) \\
\hline Moris et al & 7 & 0 & 8 & Global (2001) \\
\hline Enger et al & 9 & 5 & 0 & Portugal (2009) \\
\hline Silva et al & 65 & 0 & 4 & Turkey (2012) \\
\hline Tosun et al & 2 & 0 & 0 & Argentina \\
\hline Present study & 31 & 0 & 0 & 3 \\
\hline
\end{tabular}

(2012) [1], Tosun et al (2012) [7], (Table 8).

When the species found were associated with oral clinical conditions at the time of sampling, according to the data recorded in the medical history of each patient, it was found that C. parapsilosis sensu stricto prevailed in inflammatory oral conditions compatible with clinical gingivitis and periodontitis, predominating particularly in the latter group. Conversely, when correlating the species isolated with the use of intraoral appliances, even when C. parapsilosis sensu stricto predominated in the group of patients with some kind of intraoral appliances, the difference observed was not statistically significant in relation to non-carriers. There are no published data to contrast our results.

Antifungal resistance or tolerance of the parapsilosis species complex is a growing problem in the terms of conventional and novel antifungal agents. According to some research, isolates of C. parapsilosis sensu stricto are less susceptible to some antifungals used in candidiasis treatments, such as amphotericin (AMB), fluconazole (FLC), itraconazole (ITC) and caspofungin (CASPO) when compared to the susceptibility of isolates of $C$. orthopsilosis and C. methapsilosis. Among the azole derivatives analyzed in this study, FLC and VRC showed high levels of efficacy, as a single strain derived from the tongue showed SDD and SI to these drugs, respectively. And the $\mathrm{MIC}_{50}$ and $\mathrm{MIC}_{90}$ of both drugs was similar to that reported by other authors $[2,17,18]$.

Based on the ECV, all C. parapsilosis sensu stricto isolates were susceptible to AMB. This result is in line with other studies[19,20]. However, Ataides F et al[14] and Lockhart et al,[6] reported C. parapsilosis sensu stricto species resistance to AMB. The response of the parapsilosis species complex to AMB varies considerably from one region to another, which could be determined by genotypic variability of the three species involved in this complex.

Regarding the response to FLC obtained in this study, $100 \%$ of the isolates showed MIC values equal to or lower than $1 \mathrm{ug} / \mathrm{mL}$ of this drug. As in AMB, there is no consensus on the cut-off values for this antifungal in C. parapsilosis sensu stricto species. However, when considering the ECV classification made by
Society for Micopathology ${ }^{21}$ established as isolates "sensitive" to flucytosine, those who shed drug MIC equal to or lower than 1 $\mathrm{ug} / \mathrm{mL}$. And as reported by other authors, the MIC obtained in this study regarding flucytosine in the 15 strains analyzed is high compared to that reported by Silva et al, [3] Miranda et al,[2] and Canton et al[17]. These reports were obtained in studies conducted in Europe, while in India, Bhatt $\mathrm{M}$ et al[22] obtained high rates of FLC resistance in C. parapsilosis isolates.

In relation to echinocandins, only one isolate showed reduced susceptibility to CASPO in this study. This result is consistent with the global trend, as many studies have reported that the MIC value of CASPO in C. parapsilosis sensu stricto is higher than the values of the other two species within the complex. However, the explanation for this phenomenon is not entirely clear[14]. Recent studies have described a precise mutation in the glucan synthase (FKS) gene in the parapsilosis species complex, which may well explain this observation. FKS gene mutations have been shown to be associated with resistance to CASPO, which was demonstrated by the increase in MIC values in mutant isolates compared with those non-mutant or wild-type [23,24]. Unlike the results obtained for CASPO, all 19 strains were susceptible to MICA, and $\mathrm{MIC}_{50}$ and $\mathrm{MIC}_{90}$ coincided regarding this drug, despite being lower than that reported by other authors like Miranda et al[2] and Tosun et al[7].

\section{Conclusions}

- C. parapsilosis sensu stricto is commonly related to the colonization of the oral mucosa, especially in pathological conditions. In this context, the mouth becomes a potential source of candidemia or invasive infections caused by this yeast, besides being a possible source of fungal transmission by direct contact from person to person.

- C. metapsilosis and C. orthopsilosis are two strange species found in oral cavity niches both in healthy conditions and disease.

- C. parapsilosis sensu stricto shows a favorable response to a wide range of antifungals, with less responsiveness to FLC, VRC and CASPO. Situation that is in line with the global trend.

- In the Americas, this is the first study focused on species 
Citation: Rodríguez L and Jewtuchowicz V (2016) Molecular Characterization of Candida parapsilosis Species Complex in Niches of the Oral Cavity in a Cohort of Patients from Argentina with Different Oral and Dental Clinical Manifestations. J. Dent. Sci. Ther 1(1): 18-25. doi: https://doi. org/10.24218/jdst.2016.05.

distribution of this complex in oral cavity niches which includes a collection of more than 20 clinical isolates, besides taking into consideration the oral and dental clinical situation at the time of sampling, which has not been observed in other reports based on this subject.

\section{Recommendations}

The authors suggest applying the format of the study to a larger sample size and to a prospective model in order to validate the results reported in this study.

\section{Funding}

The study was funded by UBACyT grant 20020120200119 provided by the University of Buenos Aires.

\section{References}

1. Ge Y, Boekhout T, Zhan P, Lu G, Shen Y, Li M, et al. Characterization of the Candida parapsilosis complex in East China: species distribution differs among cities. Med Mycol. 2012; 50(1):56-66. doi: 10.3109/13693786.2011.591440.

2. Miranda I, Eraso E, Hernández J, López L, Carrillo A, Hernández $J$, et al. Prevalence and antifungal susceptibility patterns of new cryptic species inside the species complexes Candida parapsilosis and Candida glabrata among blood isolates from a Spanish tertiary hospital. J AntimicrobChemother. 2011; 66(10):2315-2322.doi: 10.1093/jac/dkr298.

3. Silva A, Miranda I, Lisboa C, Pina-Vaz C, Rodrigues A. Prevalence, Distribution, and Antifungal Susceptibility Profiles of Candida parapsilosis, C. orthopsilosis, and C. metapsilosis in a Tertiary Care Hospital. Journal of Clinical Microbiology. 2009; 47(8):2392-2397.

4. Treviño R, Garza E, Gonzáles J, Bocanegra V, Llaca J, Gonzáles G. Molecular characterization and antifungal susceptibility of the Candida parapsilosis species complex of clinical isolates from Monterrey, Mexico. Med Mycol. 2012; 50:781-784. doi: 10.3109/13693786.2012.675526.

5. Treviño R, González J, Garza E, González G. Candidaparapsilosis, unaamenazadesafiante. MedicinaUniversitaria. 2012;14(56):157-165.

6. Lockhart SR, Messer SA, Pfaller MA, Diekema DJ. Geographic distribution and antifungal susceptibility of the newly described species Candida orthopsilosis and Candida metapsilosis in comparison to the closely related species Candida parapsilosis. J ClinMicrobiol. 2008; 46(8):2659 - 2664.doi: 10.1128/JCM.00803-08.

7. Tosun I, Akyuz Z, Guler N, Gulmez D, Bayramoglu G, Kaklikkay N, et al. Distribution, virulence attributes and antifungal susceptibility patterns of Candida parapsilosis complex strains isolated from clinical samples. Med Mycol. 2012; 51(5):483-492. doi: 10.3109/13693786.2012.745953.

8. Ghannoum M, Jurevic R, Mukherjee P, Cui F, Sikaroodi M, Naqvi A, et al. Characterization of the Oral Fungal Microbiome (Mycobiome) in Healthy Individuals.PLoSPathog. 2010; 6(1):e1000713. doi: 10.1371/journal.ppat.1000713.

9. Moris D, Melhem M, Martins M, Souza L, Kacew S, Szeszs M, et al. Prevalence and antifungal susceptibility of Candida parapsilosis complex isolates collected from oral cavities of HIV-infected individuals. J Med Microbiol. 2012; 61(Pt 12):1758-1765. doi: 10.1099/jmm.0.045112-0.
10. Pfaller M, Castanheira M, Messer S, Jones R. In vitro antifungal susceptibilities of isolates of Candida spp. and Aspergillus spp. from China to nine systemically active antifungal agents: data from the SENTRY antifungal surveillance program, 2010 through 2012. Mycoses. 2015; 58(4):209-14.doi: 10.1111/myc.12299.

11. Van Asbeck E,Clemons K, Martínez M,Tong A,Stevens D. Significant differences in drug susceptibility among species in the Candida parapsilosis group. Diagnostic Microbiology and Infectious Disease. 2008; 62 (1):106-109. doi:10.1016/j.diagmicrobio.2008.04.019.

12. Asadzadeh M, Ahmad S, Al-Sweih N, Khan Z. Rapid molecular differentiation and genotypic heterogeneity among Candida parapsilosis andCandida orthopsilosis strains isolated from clinicalspecimens in Kuwait. J Med Microbiol. 2009; 58(Pt 6):745752. doi: 10.1099/jmm.0.008235-0.

13. Pfaller M, Diekema D. Progress in Antifungal Susceptibility Testing of Candida spp. by Use of Clinical and Laboratory Standards Institute Broth Microdilution Methods, 2010 to 2012. J ClinMicrobiol. 2012; 50(9):2846-2856.doi: 10.1128/JCM.00937-12.

14. Ataides FS, Costa CR, Souza LK, FernandesOd, Jesuino RS, Silva Mdo R. Molecular identification and antifungal susceptibility profiles of Candida parapsilosis complex species isolated from culture collection of clinical samples. Rev Soc Bras Med Trop. 2015; 48(4):454-9.doi: 10.1590/0037-8682-0120-2015.

15. Tavanti A, Davidson A, Gow N, Maiden M, Odds F. Candida orthopsilosis and Candida metapsilosis spp. nov.toreplace Candida parapsilosis groups II and III. J ClinMicrobiol. 2005; 43(1):284-292.

16. Banerjee B, R M SD, Baliga S. Clinico-microbiological study of candidemia in a tertiary care hospital of southern part of India. Iran J Microbiol. 2015; 7(1):55-61.

17. Canton E, Pemán J, Quindós G, Eraso E, Miranda-Zapico I, Álvarez M, et al. Prospective Multicenter Study of the Epidemiology, Molecular Identification, and Antifungal Susceptibility of Candida parapsilosis, Candida orthopsilosis, and Candida metapsilosis Isolated from Patients with Candidemia. Antimicrob Agents Chemother. 2011; 55(12):5590-5596. doi: 10.1128/AAC.00466-11.

18. Ziccardi M, Souza L, Gandra R, Galdino A, Baptista A, Nunes A, et al. Candidaparapsilosis (sensulato) isolated from hospitals located in the Southeast of Brazil: Species distribution, antifungal susceptibility and virulence attributes.Int J Med Microbiol. 2015;305(8):848-59. doi: 10.1016/j.ijmm.2015.08.003.

19. Córdoba S, Vivot W, Bosco-Borgeat ME, Taverna C, Szusz W, Murisengo $O$, et al . Species distribution and susceptibility profi le of yeasts isolated from blood cultures: results of a multicenter active laboratory-based surveillance study in Argentina. Rev Argentina Microbiol. 2011; 43(3):176-185.doi: 10.1590/S032575412011000300003.

20. Pfaller MA, Diekema DJ, Gibbs DL, Newell VA, Ng KP, Colombo A, et al. Geographic and temporal trends in isolation and antifungal susceptibility of Candida parapsilosis: a global assessment from the ARTEMIS DISK Antifungal Surveillance Program, 2001 to 2005. J ClinMicrobiol. 2008; 46(3):842-849.doi: 10.1128/JCM.02122-07.

21. British Society for Mycopathology. Laboratory methods for flucytosine (5-fluorocytosine). Report of a Working Group of the British Society for Mycopathology. J AntimicrobChemother. 1984; 14:1-8. 
Citation: Rodríguez L and Jewtuchowicz V (2016) Molecular Characterization of Candida parapsilosis Species Complex in Niches of the Oral Cavity in a Cohort of Patients from Argentina with Different Oral and Dental Clinical Manifestations. J. Dent. Sci. Ther 1(1): 18-25. doi: https://doi. org/10.24218/jdst.2016.05.

22. Bhatt M, Sarangi G, Paty B, Mohapatra D, Chayani N, Mahapatra $A$, et al. Biofilm as a virulence marker in Candida species in Nosocomial blood stream infection and its correlation with antifungal resistance.Indian J Med Microbiol. 2015; 33 Suppl:112114. doi: 10.4103/0255-0857.150909.

23. Pfaller MA, Castanheira M, Diekema DJ, Messer SA, Moet GJ, Jones RN. Comparison of European Committee on Antimicrobial Susceptibility Testing (EUCAST) and Etest methods with the CLSI broth microdilution method for echinocandin susceptibility testing of Candida species. J ClinMicrobiol. 2010; 48(5):1592-1599.doi: 10.1128/JCM.02445-09.
24. Axner-Elings $M$, Botero-Kleiven $S$, Jensen $R H$, Arendrup $M C$. Echinocandin susceptibility testing of Candida isolates collected during a 1-year period in Sweden. J ClinMicrobiol. 2011; 49(7):25162521.doi: 10.1128/JCM.00201-11.

25. Enger L, Joly S, Pujol C, Simonson P, Pfaller M, Soll D. Cloning and characterization of a complex DNA fingerprintingprobe for Candidaparapsilosis. J ClinMicrobiol. 2002; 39(2):658-669. 